\title{
Measuring Poverty Without The Mortality Paradox*
}

\author{
Mathieu Lefebvre ${ }^{\dagger}$ Pierre Pestieau ${ }^{\ddagger}$ and Gregory Ponthiere ${ }^{\S}$
}

June 29, 2012

\begin{abstract}
Under income-differentiated mortality, poverty measures reflect not only the "true" poverty, but, also, the interferences or noise caused by the survival process at work. Such interferences lead to the Mortality Paradox: the worse the survival conditions of the poor are, the lower the measured poverty is. We examine several solutions to avoid that paradox. We identify conditions under which the extension, by means of a fictitious income, of lifetime income profiles of the prematurely dead neutralizes the noise due to differential mortality. Then, to account not only for the "missing" poor, but, also, for the "hidden" poverty (premature death), we use, as a fictitious income, the welfare-neutral income, making indifferent between life continuation and death. The robustness of poverty measures to the extension technique is illustrated with regional Belgian data.

Keywords: premature mortality, income-differentiated mortality, poverty measurement, censored income profile.

JEL classification code: I32.
\end{abstract}

*The authors thank Claude D'Aspremont, Julio Davila, David de la Croix, Alexis Direr, Peter Hammond, François Maniquet, Sergio Perelman, Paolo Piacquadio, the editor and two anonymous referees for their helpful comments on this paper.

${ }^{\dagger}$ University of Liege.

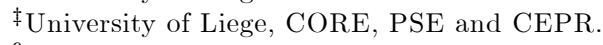

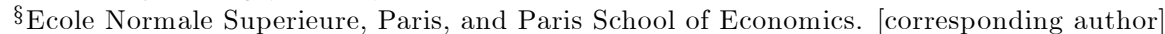
Contact: ENS, 48 Bd Jourdan, Building B, 2nd floor, Office B, 75014 Paris, France. Tel: 0033-1-43136204. E-mail: gregory.ponthiere@ens.fr 


\section{Introduction}

In An Essay on the Principle of Population (1798), Malthus emphasized that the population is a social product, whose size adjusts to the prevalence of poverty through two kinds of population "checks". On the birth side, poverty reduces fertility through parental anticipations about future difficulties to raise children (i.e. "preventive checks"). Moreover, poverty leads to premature deaths within the low income classes (i.e. "positive checks").

Given the underdeveloped state of social statistics at Malthus's time, the existence of population checks was more a conjecture than a scientific result. However, in the recent years, empirical studies confirmed the existence of positive population checks, under the form of an increasing relationship between income and life expectancy. ${ }^{1}$ On average, individuals with higher incomes have, ceteris paribus, a longer life than individuals with lower incomes. ${ }^{2}$

Income-differentiated mortality raises a twofold challenge for the measurement of poverty. Actually, the two aspects of poverty measurement underlined by Sen (1976) are affected: on the one hand, the identification of the poor within the population; on the other hand, the construction of an index aggregating and weighting the information available on the identified poor.

Regarding the identification of the poor, income-differentiated mortality leads to a paradox. Poor persons tend to die, on average, earlier than non-poor persons. Hence, usual poverty measures, which focus on living individuals, do not count the "missing" poor, and, thus, reflect not only the "true" poverty, but, also, the interferences or noise due to income-differentiated mortality. Those interferences push towards a lower poverty estimate. As a consequence, poverty measures tend to underestimate the "true" poverty. ${ }^{3}$ That problem can be called the Mortality Paradox: the worse the survival conditions faced by the poor are, the lower the measured poverty is. That result is paradoxical, since poverty measures should be increasing - or, at least, non-decreasing - in the premature mortality faced by the poor due to their low income.

Income-differentiated mortality raises also an important challenge regarding the treatment of the informational basis relevant for the measurement of poverty. Undoubtedly, a shorter life is a major source of deprivation. Hence, if individuals with lower incomes face also a higher mortality, it is hard to ignore this when measuring poverty. But if one takes premature death as a part of the poverty phenomenon to be measured, then a major issue concerns the weighting of the two dimensions under study: income and longevity.

This paper focuses on the challenges raised by income-differentiated mortality for the measurement of poverty, by re-examining the Mortality Paradox and its solutions. For that purpose, we first develop a 2-period model with income mobility and income-differentiated mortality, and study the conditions under which head-count poverty ratios face the Mortality Paradox. We propose a solution to it: the extension, by means of a fictitious income, of lifetime income

\footnotetext{
${ }^{1}$ The same cannot be said on the birth side, where the observed fertility transition has infirmed the existence of preventive population checks. Indeed, to explain the fertility decline, the substitution effect related to the rise in productivity must have overcome the income effect.

${ }^{2}$ See, among others, Duleep (1986), Deaton and Paxson (1998), Deaton (2003), Jusot (2003) and Salm (2007). One exception is Snyder and Evans (2006), who show that high income groups face, ceteris paribus, a higher mortality than low-income groups.

${ }^{3}$ This problem is general, and concerns all poverty measures, including the recent multidimensional poverty indexes (see infra).
} 
profiles of the prematurely dead. Then, we argue that a natural candidate for the fictitious income is the welfare-neutral income, i.e. the income making an agent indifferent between further life with that income and death. Finally, we use Belgian data to estimate the bias induced by the Mortality Paradox, and to evaluate the robustness of adjusted poverty measures to the extension of income profiles. This allows us to decompose the adjustment into counting the "missing" persons and valuing premature death as a part of poverty.

As far as we know, there exists only one paper, by Kanbur and Mukherjee (2007), which highlighted the existence of the Mortality Paradox. Using a broad class of poverty measures (including, among other measures, head-count ratios), Kanbur and Mukherjee showed that standard poverty indicators face serious biases under income-differentiated mortality. Income-differentiated mortality acts as a selection mechanism, which selects proportionally fewer poor persons than non-poor persons, making standard poverty measures reflect not only poverty, but, also, the noise or interferences induced by the selection process at work. Kanbur and Mukherjee also proposed a solution to the Mortality Paradox. They recommend, when computing poverty measures, to count the prematurely dead poor persons as if they were still alive, and to truncate their lifetime income profiles by means of a fictitious income depending on past incomes. Such a general remedy can be used to adjust or correct standard poverty measures: this amounts to adjust the distribution of income, in such a way as to count the "missing poor" persons as well, even though their premature death made them disappear from (unadjusted) distributions.

Our paper complements that contribution on three grounds. Firstly, whereas Kanbur and Mukherjee propose general rules for the selection of a fictitious income, we argue, on the contrary, that the fictitious income should be equal to a particular level: the welfare-neutral income. Secondly, while Kanbur and Mukherjee only truncate the income profiles among the poor population, we propose to do it for all "missing" persons. Thirdly, whereas Kanbur and Mukherjee's paper is purely theoretical, we provide empirical estimates of size of the bias induced by the Mortality Paradox, as well as an empirical study of the robustness of adjusted poverty measures to the extension technique used.

At this early stage of our study, three remarks should be made. First, there exist various circumstances where one can talk of "missing" individuals. A well-known case is the one of missing women in countries where parents get rid of their daughters through abortion or infanticide (Sen 1998). Another well-documented case is the one of missing cohorts in case of war, famine or epidemic. The case studied in this paper - missing elderly individuals due to income-differentiated mortality - is thus one case among many others. In all those cases, it would be interesting to carry out some thought experiment, to characterize the hypothetical world in which all those missing persons would be alive. This is what we do in this paper, where we study what old-age poverty measures become once the missing elderly are taken into account.

Second, although the theoretical part of this paper focuses, for the sake of simplicity, on head-count poverty measures, the measurement bias induced by income-differentiated mortality is quite general, and is faced by many standard poverty measures, as stressed by Kanbur and Mukherjee (2007). This is the reason why, when estimating the size of the measurement bias in the empirical part, we also provide estimates of the Foster Greer Thorbecke (1984) (FGT) poverty measure, with and without the inclusion of the prematurely dead persons. 
Third, it should also be stressed that the measurement problem that we consider here concerns also multidimensional poverty measures taking life expectancy statistics into account. The reason is the following. All poverty measures, including the multidimensional ones, are concerned with the assignment of some number to a situation characterized by a particular distribution of attributes among a population (e.g. income, longevity, etc.). Hence, the definition of the relevant population - whether it includes the prematurely dead persons or not - is a general issue, which concerns all poverty measures. ${ }^{4}$ Given that the measurement problem does not come from the dimensions taken into account, but from the definition of the population to be studied, multidimensional measures taking longevity into account do not avoid the Mortality Paradox. ${ }^{5}$

Anticipating on our results, we first show how, under income-differentiated mortality, standard old-age poverty rates are subject to the Mortality Paradox. We show that, when a fictitious income lower than the poverty line is assigned to prematurely dead poor individuals only, the adjusted poverty rate exhibits some form of independence with respect to variations in survival conditions. Then, we consider the construction of alternative adjusted poverty measures, which count a premature death as an aspect of deprivation and poverty. Such measures, instead of being invariant to a worsening of survival conditions, are increasing with the strength of positive population checks. That alternative solution to the Mortality Paradox consists of assigning, to all prematurely dead persons, a fictitious income equal to the welfare-neutral income. Finally, we show, on the basis of Belgian regional data, that, while the addition of the "missing" persons with fictitious incomes equal to the incomes when being alive only raises the poverty rates by about one point, the assignment of a fictitious income equal to the welfare-neutral income raises poverty rates by $6-7$ points. Taking the "hidden" burden of premature death into account is a much bigger correction than merely counting the "missing" poor. Moreover, when comparing FGT poverty measures with and without the addition of "missing" persons, we observe that the correction leads to a significant rise in the measured poverty, which is, here again, strongly sensitive to the fictitious income assigned to the prematurely dead, even more than under standard head-count poverty measures.

The paper is organized as follows. Section 2 studies the measurement of poverty in a model with income mobility and income-differentiated mortality, and identifies conditions under which truncating income profiles of the prematurely dead prevents the Mortality Paradox. Section 3 explores a particular extension, which relies on the welfare-neutral income. Section 4 illustrates, on the basis of regional Belgian data, the Mortality Paradox and the robustness of poverty measures to the extension method. Section 5 concludes.

\footnotetext{
${ }^{4}$ For instance, the Human Poverty Index (UNDP 1997), which includes, as dimensions, the probability of not surviving to ages 40 or 60, faces the Mortality Paradox, since poor persons who survive until 60 years and then die will not be counted as poor after their death, so that a poverty-related death reduces the poverty measure.

${ }^{5}$ To illustrate this, let us take the example of a deprivation index taking income and life expectancy into account. Suppose that a famine occurs. This implies an immediate reduction of life expectancy and a rise in the deprivation index. However, income and life expectancy statistics will, in the following years, reflect the living conditions among a subgroup of the initial population, i.e. the ones who survived despite the famine, and who suffer from less deprivation. Hence, the deprivation index reflects not only the actual deprivation phenomenon, but, also, the selection induced by the famine. The problem raised by the "missing" persons cannot be solved merely by taking additional dimensions into account, since the problem lies in the definition of the population for which one would like to measure deprivation.
} 


\section{Poverty measure and income-based mortality}

\subsection{The framework}

Let us consider a two-period model, where a cohort, of size $N \in \mathbb{N}$, lives the young age (first period) for sure, whereas only some fraction of the population will enjoy the old age (second period). ${ }^{6}$

There exists a finite number $K \in \mathbb{N}$ of possible income levels $(K>1)$. The set of possible income levels is: $Y=\left\{y_{1}, \ldots, y_{K}\right\}$. For the ease of presentation, we assume that income levels are indexed in an increasing order, so that:

$$
y_{1}<\ldots<y_{K}
$$

The number of young individuals with income $y_{i} \in Y$ is denoted by $n_{i}^{1} \cdot{ }^{7}$ We denote by $\mathbf{n}^{\mathbf{1}}$ the vector of size $K$, whose entries are $n_{k}^{1}$ for $k=1, \ldots, K$.

The probability of survival to the old age, denoted by $\pi$, depends on the income when being young. Following the literature, we assume that a higher income when being young leads to higher survival chances. ${ }^{8}$ Hence income-specific survival probabilities, which take $K$ distinct values, are ranked as follows:

$$
\pi_{1}<\ldots<\pi_{K}
$$

We denote by $\pi$ the vector of size $K$ whose entries are the income-specific survival probabilities $\pi_{k}$, for $k=1, \ldots, K$. The number of surviving old individuals with income $y_{i} \in Y$ is denoted by $n_{i}^{2}{ }^{9}$ We denote by $\mathbf{n}^{2}$ the vector of size $K$, whose entries are $n_{k}^{2}$ for $k=1, \ldots, K$.

Denoting by $\lambda_{i j}$ the probability that a young agent with income $y_{i}$ enjoys, in case of survival, an income $y_{j}$ at the old age, the income mobility can be described, conditionally on survival, by the right stochastic matrix $\boldsymbol{\Lambda}$ :

$$
\boldsymbol{\Lambda}=\left(\begin{array}{cccc}
\lambda_{11} & \lambda_{12} & \ldots & \lambda_{1 K} \\
\lambda_{21} & \lambda_{22} & \ldots & \lambda_{2 K} \\
\ldots & \ldots & \ldots & \ldots \\
\lambda_{K 1} & \lambda_{K 2} & \ldots & \lambda_{K K}
\end{array}\right)
$$

The income mobility matrix $\boldsymbol{\Lambda}$ concerns individuals who live the two periods. As such, this does not take premature death into account, and, thus, leads to an incomplete representation of the dynamics of income distribution.

Actually, the dynamics of income distribution can be represented by means of the transition matrix $\mathbf{M}$, of size $K \times K$, which describes how the income distribution at the young age determines the income distribution at the old age:

$$
\mathbf{n}^{2}=\mathbf{M}^{\prime} \mathbf{n}^{1}
$$

The transition matrix $\mathbf{M}$ is:

$$
\mathbf{M}=\left(\begin{array}{cccc}
\pi_{1} \lambda_{11} & \pi_{1} \lambda_{12} & \ldots & \pi_{1} \lambda_{1 K} \\
\pi_{2} \lambda_{21} & \pi_{2} \lambda_{22} & \ldots & \pi_{2} \lambda_{2 K} \\
\ldots & \ldots & \ldots & \ldots \\
\pi_{K} \lambda_{K 1} & \pi_{K} \lambda_{K 2} & \ldots & \pi_{K} \lambda_{K K}
\end{array}\right)
$$

\footnotetext{
${ }^{6}$ Our argument is robust to the number of life-periods. We focus here on a two-period framework to simplify the presentation without unnecessary material.

${ }^{7}$ We have: $\sum_{k=1}^{K} n_{k}^{1}=N$.

${ }^{8}$ See Duleep (1986), Deaton and Paxson (1998), Jusot (2003) and Salm (2007).

${ }^{9}$ We have: $\sum_{k=1}^{K} n_{k}^{2}=\sum_{k=1}^{K} \pi_{k} n_{k}^{1}$.
} 
The M matrix fully describes the trajectories of individuals in our economy. The lifecycle trajectory depends on survival probabilities and on income transition probabilities, which are correlated in terms of rank. We can easily decompose the matrix $\mathbf{M}$ into its two components: the income mobility component and the survival process component:

$$
\mathbf{M}=\boldsymbol{\Lambda} \circ \boldsymbol{\Pi}
$$

where $\boldsymbol{\Pi} \equiv \boldsymbol{\pi} \times \mathbf{1}_{\mathbf{K}}^{\prime}, \mathbf{1}_{\mathbf{K}}$ being the identity vector of size $K$, while the symbol 。 refers to the Hadamard product, that is, the entrywise product of two matrices.

The $\mathbf{M}$ matrix includes, as a special case, the situation where there is no premature death (i.e. $\pi_{i}=1$ for all $i$ ). In that case, the matrix $\mathbf{M}$ reduces to the income mobility matrix $\boldsymbol{\Lambda}$. Alternatively, if there is no mobility over the lifecycle (i.e. $\lambda_{i i}=1$ for all $i$ ), the matrix $\mathbf{M}$ is a diagonal matrix with survival probabilities $\pi_{i}$ as entries.

\subsection{The Mortality Paradox}

The Mortality Paradox is a general problem faced by various types of poverty measures. It refers to an undesirable sensitivity of poverty measures to incomedifferentiated mortality. That paradox can be stated as follows: the worse the survival conditions faced by the poor are, the lower the measured poverty is.

The origin of that paradox has to do with the selection mechanism that is at work under income-differentiated mortality. Survival laws act as a selection process: poor individuals die, on average, earlier than non-poor persons. This implies that poor persons become, with the mere passage of time, relatively less numerous than non-poor persons, yielding a lower measured poverty. That result is paradoxical, since the measured poverty should not decrease because of the mere existence of positive population checks. Actually, income-differentiated mortality can be regarded as creating some interferences or a noise preventing the measurement of the "true" poverty.

To illustrate the Mortality Paradox, let us focus on the simplest measures of poverty, i.e. head-count ratios, which measure poverty by counting the number of individuals whose incomes are below a (fixed) poverty threshold $y_{P} \in Y$.

Definition 1 Assume an economy with income distribution $\mathbf{n}^{\mathbf{i}}$ at age $i=1,2$. If $y_{P} \in Y$ is the poverty threshold, the poverty rate at age $i$ is:

$$
P^{i}=\frac{\sum_{j=1}^{P-1} n_{j}^{i}}{\sum_{k=1}^{K} n_{k}^{i}}
$$

The old-age poverty rate $P^{2}$ is subject to the Mortality Paradox. To see this, let us consider the following example. In a first situation $\left(\mathbf{n}^{\mathbf{1}}, \boldsymbol{\pi}, \boldsymbol{\Lambda}\right)$, individuals who are poor at the young age survive to the old age with positive probabilities $0<\pi_{k}<1$ for $k<P$, and there is no income mobility (i.e. $\lambda_{j j}=1$ for all $j)$. In the second situation $\left(\mathbf{n}^{\mathbf{1}}, \boldsymbol{\pi}^{\prime}, \boldsymbol{\Lambda}\right)$, individuals who are poor at the young age do not survive to the old age: $\pi_{k}^{\prime}=0$ for $k<P$, and there is no income mobility (i.e. $\lambda_{j j}=1$ for all $j$ ). Writing the old-age poverty rate as:

$$
P^{2}=\frac{\sum_{j=1}^{P-1} n_{j}^{2}}{\sum_{k=1}^{K} n_{k}^{2}}=\frac{\sum_{j=1}^{K} \pi_{j} n_{j}^{1}\left(\sum_{l=1}^{P-1} \lambda_{j l}\right)}{\sum_{k=1}^{K} \pi_{k} n_{k}^{1}}
$$


we obtain the following two measures of poverty, denoted by $P^{2}$ for the first situation and by $P^{2 \prime}$ for the second one:

$$
P^{2}=\frac{\sum_{j=1}^{P-1} \pi_{j} n_{j}^{1}}{\sum_{k=1}^{K} \pi_{k} n_{k}^{1}}>P^{2 \prime}=\frac{\sum_{j=1}^{P-1} \pi_{j}^{\prime} n_{j}^{1 \prime}}{\sum_{k=1}^{K} \pi_{k}^{\prime} n_{k}^{1 \prime}}=0
$$

The old-age poverty rate is larger in the first situation than in the second one. The lower level of measured poverty at the old age in the second situation is the mere outcome of income-differentiated mortality. The strong positive population checks at work in the second situation have made old-age poverty - apparently - disappear.

The fact that a more severe income-based mortality reduces the measured poverty is paradoxical. Poverty indexes should show us the extent of poverty, and not be disturbed by the noise due to income-based mortality. Hence the Mortality Paradox invites a refinement of poverty measures.

To avoid that paradox, one solution consists of imposing that poverty measures exhibit some independence with respect to survival conditions. The following property, entitled Robustness to Mortality Changes, captures that intuition.

Condition 1 (Robustness to Mortality Changes) A poverty measure $P^{i}$ satisfies Robustness to Mortality Changes (RMC) if and only if a deterioration of the survival conditions of some group leaves the measured poverty unchanged:

$$
\text { If }\left\{\begin{array}{l}
\pi_{k}>\pi_{k}^{\prime} \text { for some } k \leq K \\
\pi_{k}=\pi_{k}^{\prime} \text { for other } k \leq K
\end{array} \text {, then } P^{i}=P^{i \prime} .\right.
$$

RMC requires poverty measures to be invariant to a deterioration of survival conditions. That property requires to observe the impact of changes in mortality on poverty measures. A weaker independence requirement is the following.

Condition 2 (No Mobility Same Poverty) A poverty measure $P^{i}$ satisfies No Mobility Same Poverty (NMSP) if and only if, in the absence of income mobility, the measured poverty is constant across the lifecycle:

$$
\text { If } \lambda_{j j}=1 \text { for all } j \text {, then } P^{i}=P^{i+1} \text {. }
$$

NMSP states that, if we consider an economy without income mobility, the poverty rate should be constant across the lifecycle. NMSP is simpler than RMC, since it focuses on the basic case of no income mobility. However, despite its simplicity, NMSP is useful, since it has a simple logical relationship with $\mathrm{RMC}$, as shown in the following lemma.

Lemma 1 • $R M C \Longrightarrow N M S P$.

- NMSP + No income mobility $\Longrightarrow R M C$.

Proof. See the Appendix.

RMC and NMSP conditions are not equivalent. It is only in the absence of income mobility that a strict equivalence holds. In some sense, NMSP is a weaker requirement than $\mathrm{RMC}$, since it is a weaker way to formalize the idea of independence of poverty measures from survival conditions. 
Lemma 1 will allow us, when studying whether a poverty measure satisfies $\mathrm{RMC}$ or not, to focus on the hypothetical case where there is no income mobility, and to check whether NMSP is satisfied or not. If the poverty rate is not, in the absence of mobility, constant along the lifecycle, this implies that RMC is violated.

As it is shown below, the old-age poverty rate $P^{2}$ does not satisfy RMC, and is thus subject to the interferences induced by income-differentiated mortality.

Proposition $1 P^{2}$ does not satisfy NMSP, since $P^{1}>P^{2}$ without income mobility.

Proof. See the Appendix.

Hence, as a consequence of Lemma 1, we know that the old-age poverty rate violates also RMC, and, thus, is not robust to a deterioration of the survival conditions faced by the poor. The old-age poverty rate $P^{2}$ is thus subject to the Mortality Paradox.

\subsection{A general solution to the Mortality Paradox}

The reason why poverty measures suffer from the Mortality Paradox has to do with the fact that, once dead, poor persons disappear from the population. Therefore, as suggested by Kanbur and Mukherjee (2007), a solution to the Mortality Paradox comes from the extension of lifetime income profiles, to take into account the persons subject to premature mortality.

The underlying idea is the following. Instead of computing old-age poverty measures on the basis of the surviving persons only, one should do as if all individuals are still alive at the old age, and benefit from some income. For that purpose, lifetime income profiles must be extended, to assign some income to prematurely dead persons.

The assignment of a fictitious income to the premature dead implies that we have now two, instead of one, income transition matrices: one for individuals who survived to the old age, i.e. $\boldsymbol{\Lambda}$, and one for those who did not survive. We will denote that latter income transition matrix by $\boldsymbol{\Sigma}$, of size $K \times K$ :

$$
\boldsymbol{\Sigma}=\left(\begin{array}{cccc}
\sigma_{11} & \ldots & \ldots & \sigma_{1 K} \\
\ldots & \ldots & \ldots & \ldots \\
\ldots & \ldots & \ldots & \ldots \\
\sigma_{K 1} & \ldots & \ldots & \sigma_{K K}
\end{array}\right)
$$

where $\sigma_{i j}$ is the probability, for an individual with income $y_{i}$ when being young, to have a fictitious income $e_{i}=y_{j}$ assigned to him when he is dead.

The adjusted old-age poverty rate, denoted by $\hat{P}^{2}$, can be written as:

$$
\hat{P}^{2}=\frac{\sum_{i=1}^{K} \pi_{i} n_{i}^{1}\left(\sum_{j=1}^{P-1} \lambda_{i j}\right)+\sum_{i=1}^{K}\left(1-\pi_{i}\right) n_{i}^{1}\left(\sum_{j=1}^{P-1} \sigma_{i j}\right)}{\sum_{k=1}^{K} n_{k}^{1}}
$$

The first term of the numerator is standard: it counts the poor individuals among the old (surviving) population. But the second term is less standard: it counts the poor individuals among those who did not survive, their fictitious incomes being assigned to them through the matrix $\boldsymbol{\Sigma}$. 
The adjusted poverty rate $\hat{P}^{2}$ can take distinct forms, depending on: (1) whether the assignment of fictitious incomes concerns all individuals or only the initially poor; (2) whether fictitious incomes exceed or are below the poverty line $y_{P}$. Those two features of the extension are captured by the matrix $\boldsymbol{\Sigma} .^{10}$

The next proposition examines the conditions on $\boldsymbol{\Sigma}$ under which $\hat{P}^{2}$ avoids the Mortality Paradox. As above, we rely here on NMSP since we know, by Lemma 1 , that a violation of that property leads to a violation of RMC. ${ }^{11}$

Proposition 2 I: A fictitious income $e_{i}$ is assigned to the dead poor only.

- Ia: If $e_{i}<y_{P}$ for all $i, \hat{P}^{2}$ satisfies NMSP: $\hat{P}^{2}=P^{1}$.

- Ib: If $e_{i}<y_{P}$ for $i<R \leq P$ and $e_{i} \geq y_{P}$ for $i \geq R, \hat{P}^{2}$ does not satisfy NMSP: $\hat{P}^{2}<P^{1}$.

- Ic: If $e_{i} \geq y_{P}$ for all $i, \hat{P}^{2}$ does not satisfy NMSP: $\hat{P}^{2}<P^{1}$.

II: A fictitious income $e_{i}$ is assigned to all dead individuals.

- IIa: If $e_{i}<y_{P}$ for all $i, \hat{P}^{2}$ does not satisfy $N M S P: \hat{P}^{2}>P^{1}$.

- IIb: If $e_{i}<y_{P}$ for $i<R \leq P$ and $e_{i} \geq y_{P}$ for $i \geq R, \hat{P}^{2}$ does not satisfy NMSP: $\hat{P}^{2} \gtrless P^{1}$.

- IIc: If $e_{i} \geq y_{P}$ for all $i, \hat{P}^{2}$ does not satisfy $N M S P: \hat{P}^{2}<P^{1}$.

Proof. See the Appendix.

When fictitious incomes are assigned only to the prematurely dead poor persons, and when all fictitious incomes are lower than the poverty line, $\hat{P}^{2}$ satisfies NMSP, and, thus, satisfies some weak form of independence with respect to survival conditions. In all cases except Ia, the NMSP is violated, implying, by Lemma 1, a violation of RMC. Two kinds of sensitivity can arise, and these do not have the same relationship with the Mortality Paradox.

On the one hand, if the fictitious income exceeds the poverty threshold (i.e. cases Ib, Ic, IIc), the old-age poverty rate does not satisfy RMC, and is subject to the Mortality Paradox. In that case, $\hat{P}^{2}$ is, despite the adjustment, lower than $P^{1}$, since only a subgroup of the prematurely dead poor persons are counted as poor in the adjusted measure.

On the other hand, if fictitious incomes are assigned to all prematurely dead persons (i.e. cases IIa), $\hat{P}^{2}$ is not invariant to mortality changes. $\hat{P}^{2}$ is then higher than the poverty rate at the young age, because we count all prematurely dead persons as poor. Hence the Mortality Paradox does not hold here. It is quite the opposite, since $\hat{P}^{2}$ does not only count the "missing" poor, but counts also premature death as a part of the poverty phenomenon to be measured. ${ }^{12}$

Finally, let us notice a special case where the two reasons why $\hat{P}^{2}$ violates NMSP go in opposite directions. It can be shown that, under particular circumstances, those reasons cancel each other, making $\hat{P}^{2}$ satisfy NMSP. ${ }^{13}$

\footnotetext{
${ }^{10}$ The level of the fictitious income (i.e. point (2)) depends on the entries of the $\boldsymbol{\Sigma}$ matrix, whereas the subset of prematurely dead to which some fictious income is assigned is captured by the size of $\boldsymbol{\Sigma}$. For instance, assignment only to the dead poor yields $\boldsymbol{\Sigma}$ of size $(P-1) \times$ $(P-1)$, against a size $K \times K$ for an assignment for the whole prematurely dead population.

${ }^{11}$ We assume, for the simplicity of presentation, that the poverty line $y_{P}$ is invariant to the adjustment. Alternatively, if one considers a relativistic view of poverty, it could be argued that the adjustment affects also the poverty line. Given that this second-order effect depends on the precise way in which the poverty line is computed, we leave that discussion to the empirical example of Section 4.

${ }^{12}$ We will come back on that extension - and its justifications - below.

${ }^{13}$ That special case includes the situation where the matrix assigning fictitious incomes, i.e.
} 
Corollary 1 When (1) a fictitious income is assigned to all prematurely dead persons; (2) the fictitious income is inferior to $y_{P}$ for all short-lived poor individuals, and is superior to $y_{P}$ for all short-lived non-poor individuals, $\hat{P}^{2}$ satisfies NMSP. That case coincides with case IIb with $R=P$.

Proof. See the Appendix.

In sum, this section shows that it is possible to achieve some weak independence with respect to survival conditions - under the form of NMSP - by extending the lifetime income profiles of the prematurely dead. That extension can be done in various ways, but it should concern either only the prematurely dead poor individuals, with fictitious incomes below the poverty threshold, or every prematurely dead, but with fictitious incomes below the poverty line only for prematurely dead poor individuals. Otherwise, NMSP is violated.

Finally, it should be stressed here that the solution proposed by Kanbur and Mukherjee (2007), when applied to simple head-count poverty ratios, satisfies NMSP, since it coincides with case Ia in Proposition 2. The NMSP property captures some aspect of independence of poverty measures with respect to survival conditions. However, as stated in Lemma 1, NMSP does not guarantee, in a general context with income mobility, RMC. Hence, if one focuses on head-count poverty measures, Kanbur and Mukherjee's solution to the Mortality Paradox leads to RMC only if there is no income mobility, but not otherwise.

\section{The extension of income profiles revisited}

The previous section identified conditions under which truncating income profiles of the dead makes standard (head-count ratio) poverty measures avoid the Mortality Paradox. That solution, although appealing, faces some criticisms, which concern both the selection and meaningfulness of the fictitious incomes used in the extension.

A first criticism is that, even if one sticks to the extension described above, there exist not a single, but numerous ways to truncate the lifetime income profiles of the prematurely dead. The problem is that the resulting poverty estimates are likely to be strongly sensitive to the chosen fictitious income $e_{i}$. The closer $e_{i}$ is to $y_{P}$, the lower the measured poverty is. Hence, the measurement of poverty in real environments requires more precise information. ${ }^{14}$

A second criticism concerns the extent to which premature mortality per se matters for poverty measurement. Once lifetime income profiles are extended, the fictitious income enters the poverty measure as if it was an income enjoyed

$\overline{\boldsymbol{\Sigma}}$, coincides with the income mobility matrix $\boldsymbol{\Lambda}$. Indeed, in that case, we have:

$$
\hat{P}^{2}=\frac{\sum_{i=1}^{K} n_{i}^{1}\left(\sum_{j=1}^{P-1} \lambda_{i j}\right)}{\sum_{k=1}^{K} n_{k}^{1}}
$$

It is easy to check that this adjusted poverty rate satisfies No Mobility Same Poverty.

${ }^{14}$ That critique applies not only to the extension discussed above, but, also, to what was proposed by Kanbur and Mukherjee (2007). According to them, the fictitious income has to satisfy three properties: (1) it is increasing in the past income (i.e. $y_{i}>y_{i-1} \Longrightarrow e_{i}>e_{i-1}$ ); (2) it cannot exceed the past income (i.e. $e_{i} \leq y_{i}$ ); (3) agents who are not poor when being alive should not be counted as poor after the extension (i.e. $e_{i} \geq y_{P}$ when $y_{i}>y_{P}$ ). Those conditions imply that the poverty measure falls under case Ia, and escapes from the Mortality Paradox. However, those conditions are too general for measurement exercises. 
by a living person. This amounts to regard as equivalent two situations that are quite different: on the one hand, being alive with some income $y_{i}$, and, on the other hand, being dead with a fictitious income $e_{i}$ equal to $y_{i}$. Hence the extension of lifetime income profiles has a double effect. This does not only allow to count some - otherwise missing - poor in the measure of poverty. The extension assigns also some weights to two dimensions of poverty (income and longevity). Such a weighting exercise cannot remain implicit, but should have some explicit (welfare) foundations.

Those two criticisms invite a method to select a particular fictitious income, and to solve the trade-offs, in terms of poverty measurement, between low incomes and short lives. This is the task of the present section.

\subsection{A welfare-neutral fictitious income}

To overcome those two criticisms, we propose here to carry out the computation of fictitious incomes on the basis of individual preferences on lifetime income profiles. More precisely, we propose to solve those problems by selecting a particular fictitious income: the welfare-neutral income. This is defined as the hypothetical income that would make an individual indifferent between, on the one hand, further life with that income, and, on the other hand, death.

The reliance on individual preferences requires some justifications. Actually, the Mortality Paradox is a paradox only to the extent that premature death is a part of the poverty phenomenon to be measured. If premature death had nothing to do with poverty, then there would be nothing paradoxical in having poverty measures decreasing once survival conditions deteriorate. But the will to overcome the Mortality Paradox pushes us de facto in the field of multidimensional poverty measurement. Hence, it is hard to ignore individual preferences as providing an adequate informational basis for weighting the two dimensions of poverty (income and longevity). Indeed, if the level of the fictitious income contributes to assign a specific "weight" reflecting the contribution of premature death to poverty, then using individual preferences is the natural way to solve that weighting exercise.

To define that welfare-neutral income, let us assume that individuals have well-defined preferences over all possible lifetime income profiles, and that those preferences can be represented by a non-decreasing function $U(\cdot):{ }^{15}$

$$
U\left(u_{i}^{1}, u_{j}^{2}\right)
$$

where $u_{i}^{t}$ is the value assigned by a state-dependent temporal utility function at period $t$ under temporal income $y_{i}$ :

$$
u_{i}^{t}=\left\{\begin{array}{l}
u\left(y_{i}\right) \text { if the individual is alive at that period } \\
\Omega \text { if the individual is not alive at that period }
\end{array}\right.
$$

where $u(\cdot)$ is increasing, while $\Omega$ is the utility of being dead. ${ }^{16}$

Assuming the existence of a well-defined preference ordering on all possible lifetime income profiles (including profiles with different lengths) may seem, at first glance, to be a strong assumption. Note, however, that one can interpret

\footnotetext{
${ }^{15}$ For the sake of simplicity, we assume that preferences are uniform.

${ }^{16}$ That number is, in most applications, set to zero (see Becker et al 2005).
} 
those preferences as preferences over a particular subset of all possible lotteries of life, subset which only includes degenerate lotteries of life, i.e. lotteries with one certain lifetime income profile. ${ }^{17}$ In the light of this, our assumption is in line with what is generally done in economics. Actually, assuming well-defined preferences on lotteries of life is a usual practice in the empirical literature on the value of a statistical life (Viscusi 1998), and, also, in the literature on the evaluation of mortality risk reduction (Usher 1980, Becker et al 2005). ${ }^{18}$

On the basis of that, one can define the "welfare-neutral" income as follows.

Definition 2 For an individual with income $y_{i} \in Y$, the welfare-neutral income $\bar{y}_{i}$ is the hypothetical income that makes him indifferent between life continuation with that income and death:

$$
U\left(u\left(y_{i}\right), \Omega\right)=U\left(u\left(y_{i}\right), u\left(\bar{y}_{i}\right)\right)
$$

Note that whether the welfare-neutral income $\bar{y}_{i}$ is higher or lower than the income when alive $y_{i}$ is an open issue. The answer depends on the individual's preferences (i.e. the shape of the functions $U(\cdot)$ and $u(\cdot)$ ), and on the income $y_{i}$ enjoyed at the young age.

Having defined the welfare-neutral income $\bar{y}_{i}$, let us now explain why it is a plausible candidate for the extension of lifetime income profiles of the prematurely dead. For that purpose, we will show how the welfare-neutral income provides a solution to the two criticisms formulated above, by considering the welfare consequences of the extension of lifetime income profiles.

Actually, when one truncates an agent's income profile $\left(y_{i}, 0\right)$ with a fictitious income $e_{i}$, this amounts to do as if that person was still alive during that period, and enjoyed an income $e_{i}$. Thus, the hypothetical situation after extension can be better or worse than the actual situation depending on whether:

$$
U\left(u\left(y_{i}\right), \Omega\right) \lessgtr U\left(u\left(y_{i}\right), u\left(e_{i}\right)\right)
$$

If the RHS exceeds the LHS, the person would have preferred living one more period with the fictitious income rather than dying after the young age. If the LHS exceeds the RHS, the person thinks that his actual life is better than the same life with the addition of one period with income $e_{i}$. In the former case, the extension of the income profile amounts to do as if the person had enjoyed a better life than the one he actually enjoyed. In the latter case, it is the opposite. But in any case, the extension disconnects the measurement of poverty from the measurement of welfare, which is problematic.

To illustrate this, let us compare three cases.

- Case A: an individual with income $y_{i}<y_{P}$ dies after period 1 , and no extension is made in the poverty measure.

- Case B: an individual with income $y_{i}<y_{P}$ dies after period 1 , but his income profile is extended by means of the income $\tilde{e}_{i}<y_{P}$ such that:

$$
U\left(u\left(y_{i}\right), \Omega\right)<U\left(u\left(y_{i}\right), u\left(\tilde{e}_{i}\right)\right)
$$

\footnotetext{
${ }^{17}$ On that particular point, see Fleurbaey et al (2011).

${ }^{18}$ Having stressed this, it remains that assuming well-defined preferences on lives of different lengths is, from a philosophical perspective, far from trivial. Actually, it could be argued that man's capacity to evaluate a world where he / she is absent, in comparison to a world where he / she is present may be quite limited. On the difficulties involved by such comparisons, see Parfit (1984).
} 
- Case C: an individual with income $y_{i}<y_{P}$ dies at the end of period 2, and enjoys the income $y_{j}=\tilde{e}_{i}<y_{P}$ at the old age.

The measured poverty is lower in Case A than in Case B. The measured poverty is also lower in Case $\mathrm{A}$ than in Case $\mathrm{C}$, since Case $\mathrm{C}$ is equivalent to Case $\mathrm{B}$ for the measurement of poverty. Hence we have: $P^{2 A}<P^{2 B}=P^{2 C}$. In welfare terms, Cases $\mathrm{A}$ and $\mathrm{B}$ are equivalent, since these differ only in how poverty is measured, and are exactly the same otherwise. Case $\mathrm{C}$ dominates the other cases in welfare terms (because of the above inequality). Thus we have: $U^{A}=U^{B}<U^{C}$. Hence, the death of the individual, i.e. the passage from $\mathrm{C}$ to $\mathrm{B}$, reduces his welfare, but does not change the measured poverty. This is quite problematic. Clearly, if a society undergoes an epidemy, so that many individuals shift from Case $\mathrm{C}$ to Case B, it is hard to claim, despite the fall in social welfare, that poverty is, at the end, the same as if the epidemic had not occurred. Such a claim is surely subject to the Mortality Paradox. The constancy of the measured poverty despite a change in living conditions is acceptable only if that change is welfare-neutral.

Actually, there exists only one level of the fictitious income $e_{i}$ that avoids that problem. It is the "welfare-neutral" income $\bar{y}_{i}$. It is easy to see that, when $e_{i}=\bar{y}_{i}$, there is no discrepancy between poverty measurement and welfare measurement. Indeed, if we now assume $e_{i}=\bar{y}_{i}$, we still get that poverty is larger under Cases $\mathrm{B}$ and $\mathrm{C}$ than under Case A, i.e. $P^{A}<P^{B}=P^{C}$. In welfare terms, we have that Cases $\mathrm{A}$ and $\mathrm{B}$ are still equivalent (since the only change concerns how poverty is measured), but that welfare in Case $\mathrm{C}$ is also equal to what it is in Case B, since, by definition, survival with the fictitious income does not constitute a welfare improvement. Hence we have: $U^{A}=U^{B}=U^{C}$.

Thus, poverty is the same in B and $\mathrm{C}$, and welfare too. Here there is nothing shocking in having a constant poverty measure despite the occurrence of an event such as an epidemic, since that event is here welfare-neutral, unlike what prevailed above. Here the comparison of Cases B and C consists of comparing the emergence of an epidemic with its avoidance at the cost of extreme misery (leading individuals to indifference between life and death). Those two situations are equivalent in terms of poverty, and the Mortality Paradox does not arise.

In sum, the use of the welfare-neutral income as a fictitious income allows us to base the extension on a specific fictitious income, as well as to avoid a discrepancy between the measurement of poverty and the measurement of welfare. As such, this brings an appealing solution to the Mortality Paradox.

\subsection{A specific case: time-additive welfare}

The "welfare-neutral" fictitious income $\bar{y}_{i}$ depends on the postulated preferences, which can take various forms. However, under standard time-additive lifetime welfare, the welfare-neutral income $\bar{y}_{i}$ has two convenient properties. On the one hand, it is unique; on the other hand, it is independent from past income.

To see this, let us assume that lifetime welfare takes a time-additive form:

$$
U\left(u_{i}^{1}, u_{j}^{2}\right)=u_{i}^{1}+\beta u_{j}^{2}
$$

where $\beta$ is a time preference factor $(0<\beta<1)$. Then, if the utility of death is 
normalized to zero (i.e. $\Omega=0$ ), we have

$$
U\left(u_{i}^{1}, 0\right)=u_{i}^{1}+0=u\left(y_{i}\right)
$$

Hence, the welfare-neutral income $\bar{y}_{i}$, is implicitly defined by:

$$
u\left(\bar{y}_{i}\right)=0
$$

An additional life-period with income larger than $\bar{y}_{i}$ is worth being lived, whereas a life-period with income lower than $\bar{y}_{i}$ is not. Under that specification, the fictitious income $\bar{y}_{i}$ is such that temporal welfare is zero, that is, equivalent to the temporal welfare associated to death. Thus, in that case, the welfareneutral income $\bar{y}_{i}$ is the same for all past income levels. In the rest of this section, we will denote it by $y_{N}$. As a consequence, it appears that, under standard time-additive lifetime utility, the welfare-neutral income level is unique and independent from past incomes. Note that those properties may not hold under alternative, less standard, preferences. ${ }^{19}$

\subsection{Properties of the new adjusted poverty measure}

Let us now study whether adjusted poverty measures based on welfare-neutral fictitious incomes are robust to changes in survival conditions. Remind that the adjusted old-age poverty rate $\hat{P}^{2}$ is now computed by assigning a single value i.e. the welfare-neutral fictitious income - for the second-period income for all prematurely dead individuals.

As explained above, whether the welfare-neutral fictitious income lies above or below the past income when alive depends on individual preferences, and on the past income level. Therefore the transition matrix $\boldsymbol{\Sigma}$ can take various forms. Note, however, that, in the case of time-additive lifetime welfare, the welfareneutral income takes a single value, denoted by $y_{N}$, which is independent from past incomes. Hence $\boldsymbol{\Sigma}$ takes a simple form, where $\sigma_{i j}=0$ for $j \neq N$ and $\sigma_{i N}=1$ for all $i$, and the adjusted poverty rate $\hat{P}^{2}$ can be written as:

$$
\begin{aligned}
\hat{P}^{2}=\frac{\sum_{i=1}^{K} \pi_{i} n_{i}^{1}\left(\sum_{j=1}^{P-1} \lambda_{i j}\right)+\sum_{i=1}^{K}\left(1-\pi_{i}\right) n_{i}^{1}}{\sum_{k=1}^{K} n_{k}^{1}} & \text { if } y_{N}<y_{P} \\
\hat{P}^{2}=\frac{\sum_{i=1}^{K} \pi_{i} n_{i}^{1}\left(\sum_{j=1}^{P-1} \lambda_{i j}\right)}{\sum_{k=1}^{K} n_{k}^{1}} & \text { if } y_{N} \geq y_{P}
\end{aligned}
$$

In the former case, the prematurely dead persons are all counted as poor. In the latter case, they all disappear from the poverty measure. The interpretation of those two cases is as follows. When $y_{N}<y_{P}$, an individual enjoying an income

\footnotetext{
${ }^{19}$ To see this, take the following forms, which only regard either the worst or the best period lived (see Broome 2004, p. 228):

$$
\begin{aligned}
& U\left(u_{i}^{1}, u_{j}^{2}\right)=\min \left\{u_{i}^{1}, u_{j}^{2}\right\} \\
& U\left(u_{i}^{1}, u_{j}^{2}\right)=\max \left\{u_{i}^{1}, u_{j}^{2}\right\}
\end{aligned}
$$

Under the min specification, $\bar{y}_{i}$ is such that $u\left(\bar{y}_{i}\right) \geq u_{i}^{1}$, which implies $\bar{y}_{i} \geq y_{i}$, but does not allow us to say more. On the contrary, under the max specification, we have $\bar{y}_{i} \leq y_{i}$. Thus the uniqueness and the independence of the welfare-neutral income from past income are not general properties, but only nice corollaries of standard time-additive lifetime welfare.
} 
equal to the poverty line still prefers that life to death, whereas, when $y_{N} \geq y_{P}$, the poverty threshold is lower than the welfare-neutral income level, revealing that the misery makes life not worth being lived.

To identify the conditions under which the so-constructed adjusted poverty measure $\hat{P}^{2}$ is subject to the Mortality Paradox, we will, as above, examine whether $\hat{P}^{2}$ satisfies NMSP, since it is a simple way to see whether $\hat{P}^{2}$ is robust to changes in survival conditions.

Proposition 3 Consider an economy with time-additive lifetime welfare.

- Under $y_{N}<y_{P}, \hat{P}^{2}$ does not satisfy NMSP: $\hat{P}^{2}>P^{1}$.

- Under $y_{N} \geq y_{P}, \hat{P}^{2}$ does not satisfy NMSP: $\hat{P}^{2}<P^{1}$.

Proof. See the Appendix.

Thus, once the fictitious income takes its welfare-neutral level and is assigned to all prematurely dead individuals, $\hat{P}^{2}$ does not satisfy NMSP, and, by Lemma 1, also violates RMC. That lack of robustness occurs, since the extension based on the welfare-neutral fictitious income amounts to count early deaths as a source of the poverty phenomenon to be measured. The sensitivity of adjusted poverty measure to survival conditions has two meanings.

When $y_{N}$ lies below the poverty threshold $y_{P}$, all premature deaths are regarded as a source of poverty, and this explains why $\hat{P}^{2}$ is sensitive to a deterioration of survival conditions. Thus, adjusted poverty measures, instead of being invariant to changes in income-based mortality, take differential mortality into account, in the opposite way as standard poverty measures do. This explains why $\hat{P}^{2}$ violates the RMC in that case.

If, on the contrary, the welfare-neutral income level exceeds the poverty threshold, the adjusted poverty measure at the old age is lower than the poverty measure at the young age. The intuition is that, in that case, life is not worth being lived for all poor persons. As a consequence, in that context, premature death cannot be counted as something causing poverty, and the Mortality Paradox is hardly relevant under those circumstances.

In sum, this Section proposed to overcome the Mortality Paradox by truncating lifetime income profiles of the prematurely dead by means of the welfareneutral income. The use of the welfare-neutral income as a fictitious income can be defended on two grounds. First, the computation of an income that yields indifference between life and death leads, under standard preferences, to a unique value for the fictitious income. Such a uniqueness is most welcome when we consider the empirical measurement of poverty, which is strongly sensitive to the fictitious income (see below). Second, the so-computed fictitious income can also, thanks to its welfarist foundations, sort out trade-offs between income and longevity. As such, this adjustment of poverty measures does more than counting the "missing" individuals; it also takes into account a "hidden" but central - part of the poverty phenomenon to be measured: premature death.

\section{Old-age poverty in Belgian regions}

Let us now illustrate the downward bias due to the Mortality Paradox, and the sensitivity of adjusted old-age poverty measures to the extension of income profiles. For those purposes, we will use data from Belgium and its regions. 


\subsection{The data}

We use raw poverty measures coming from the European household survey EUSILC for the year 2006 (EU, 2006). Regarding longevity data, the empirical study of the Mortality Paradox ideally requires lifetables differentiated according to income groups. Such lifetables are not available, but these are derived from education-specific lifetables from Deboosere et al. (2009)..$^{20}$

Since the Mortality Paradox is about the effect of differentiated survival conditions on poverty measurement, one can expect that measurement biases induced by income-differentiated mortality are more negligible at younger ages. Therefore, to estimate the biases due to differentiated mortality, we will focus on the measurement of poverty in the population aged 60 or more. Table 1 presents the head-count poverty rates by region and by age groups in 2006 .

Poverty is higher among those of age 60 and more than among the total population. While the total poverty rate is $14.2 \%$, the proportion of poor elderly is $20.8 \%$. There exist also large differences between men and women. Whatever the region and the age group are, poverty rates are larger among women than among men. That gender poverty gap is particularly high above the age of 60 . Table 1 highlights also a big difference between Flanders and Wallonia. That gap is important among the younger generations, but tends to vanish at older age, thanks to the (nationwide) pension system.

Table 1 also shows life expectancy differentials between men and women, and between Flanders and Wallonia. Whereas the gender gap in life expectancy is well documented, the geographical gap is more surprising. Indeed, although both regions are geographically close to each other, life expectancy at birth in Wallonia is shorter than in Flanders, by about 2 years and a half.

\begin{tabular}{cccc} 
Table 1 : Poverty and life expectancy in Belgium & 21 \\
\hline \hline & Belgium & Flanders & Wallonia \\
\hline Poverty rate & & & \\
\hline Total population & $14.2 \%$ & $11.5 \%$ & $16.0 \%$ \\
Male & $12.9 \%$ & $10.1 \%$ & $15.0 \%$ \\
Female & $15.4 \%$ & $12.9 \%$ & $16.9 \%$ \\
$60+$ & $20.8 \%$ & $20.2 \%$ & $20.4 \%$ \\
Male & $18.7 \%$ & $18.3 \%$ & $18.9 \%$ \\
Female & $22.4 \%$ & $21.9 \%$ & $21.6 \%$ \\
\hline Life expectancy & & & \\
\hline Total population & 79.4 & 80.2 & 77.9 \\
Male & 76.5 & 77.6 & 74.6 \\
Female & 82.2 & 82.8 & 81.1 \\
\hline \hline
\end{tabular}

Besides gender and geographic location, another source of longevity inequality is the income. However, the impact of income on mortality is more difficult to observe, since there exist no income-specific lifetable. Hence, in order to derive a relation between income and mortality, we use lifetables by educational

\footnotetext{
${ }^{20}$ See the Appendix.

${ }^{21}$ Those poverty rates are computed on the basis of the annual available equivalent income calculated with OECD equivalence scales (see the Appendix). The poverty rate is the percentage of the population below the poverty threshold fixed at $60 \%$ of the median income (threshold $=10236 €$ ).
} 
level, which are regularly published, and the correlations between education and income, to extrapolate lifetables by income levels, for each region and gender.

While our calculations are presented in the Appendix, Figures 1 and 2 below summarize our results by showing life expectancy at age 55-59 by income class, for males and females in Flanders and in Wallonia.

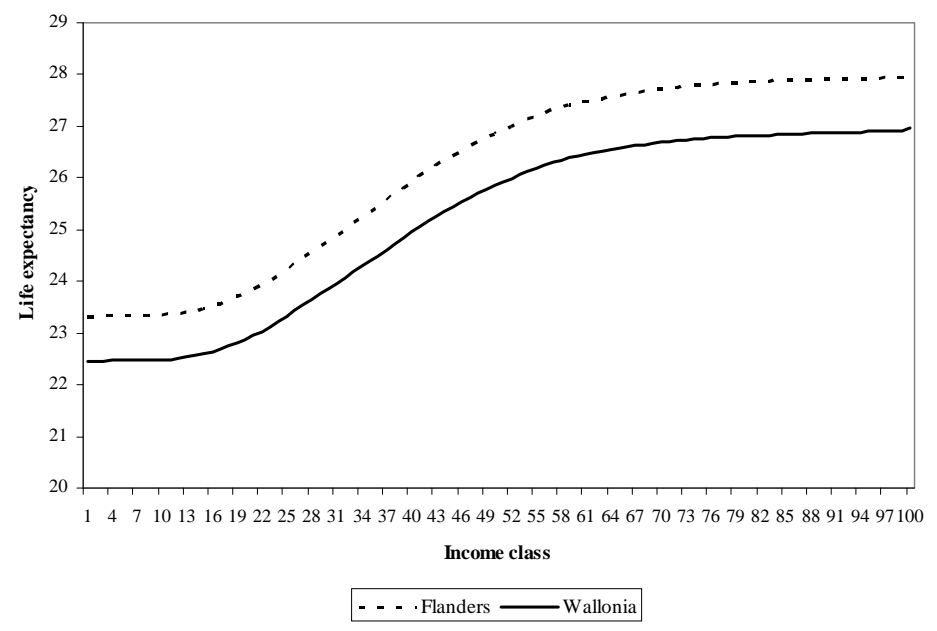

Figure 1 : Life expectancy at 55-59 by income class Male

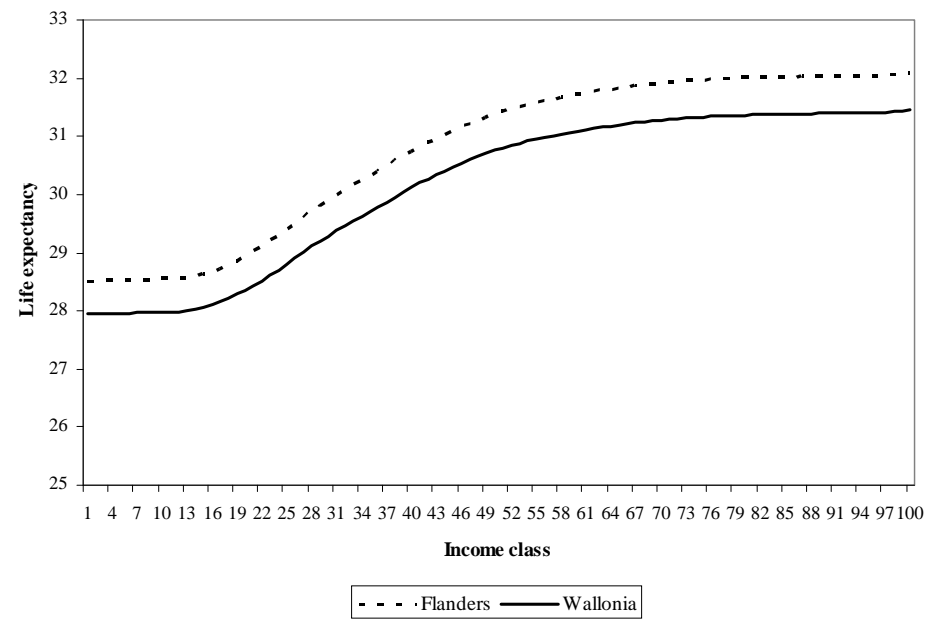

Figure 2 : Life expectancy at 55-59 by income class Female

Those figures invite several comments. First, there exists an increasing monotonic relationship between income and life expectancy at age 55-59. That relationship is robust to all genders and regions, and is significant. For instance, a Walloon man in the lowest income class has a life expectancy that is 4 years 
less than the one of a Walloon man of the highest income group. Second, the income / longevity relationship is non-linear: it is between the second and the sixth deciles that the slope is the largest. But at the two extremes of the income distribution, the income / longevity relationship is less strong. Thirdly, the comparison of Figures 1 and 2 suggests that the income / longevity relationship is significantly stronger for men than for women.

In the light of Figures 1 and 2, one can expect that standard poverty measures at high ages are biased downwards. The reasons are twofold.

A first reason has to do with the selection mechanism induced by incomedifferentiated mortality. Given that poor persons tend to live less long than nonpoor persons, the poverty rate among the surviving population at age 60 and more reflects not only the "true" poverty, but, also, the interferences associated with the differentiated survival process. That noise tends to reduce the apparent poverty, by the mere absence of the "missing" poor. Hence the poverty rate among Walloon males, equal to $20.4 \%$, tends, by being based on the population surviving to age 60 , to forget the "missing" poor, who faced worse survival conditions than the average because of their poverty.

Besides that measurement problem - i.e. the Mortality Paradox -, one may also argue that a premature death is a part of the poverty phenomenon to be measured. Once it is acknowledged that a Walloon male of the lowest income class lives, on average, 4 years less than one of the highest income class, why should we restrict the measurement of poverty to the income dimension?

Those problems invite distinct adjustments of poverty measures. This section compares adjusted old-age poverty measures obtained by truncating the income profiles of the prematurely dead, under various extension techniques.

\subsection{General methodology}

The adjustment of poverty measures includes two parts. First, the addition of the "missing" poor; second, the imputation of a particular fictitious income.

Regarding the first step, we use the following method. For each income class $i$ and region $r=F, W$, we have increased the population group $N_{i r}$ on the basis of the largest life expectancy observed (i.e. the one of top income levels in Flanders). After correction, the adjusted population group is:

$$
\hat{N}_{i r}=N_{i r} \frac{L_{100 F}}{L_{i r}}
$$

where $\hat{N}_{i r}$ is the adjusted population group, $N_{i r}$ is the raw population group, $L_{100 F}$ is the life expectancy of the top income group in Flanders, and $L_{i r}$ is the life expectancy for income group $i$ in region $r$.

The above computation gives us a new distribution of the population in terms of income, which is the income distribution in the hypothetical case where all individuals had faced the same survival conditions as the ones of a group of reference (top earnings in Flanders). That computation allows us to reintegrate, in our calculations, the missing persons, equal, for each group, to $\hat{N}_{i r}-N_{i r}$.

Under such a computation, the fictitious income assigned to a prematurely dead individual coincides with his past income. As we discussed above, that extension technique, although attractive, is not the unique possible one. It is indeed possible to reallocate the missing persons $\hat{N}_{i r}-N_{i r}$ of each group $i$ 
and region $r$ to any income group, and, in particular, to the welfare-neutral income group. Hence, in the following, we present adjusted poverty measures under those two adjustment techniques. ${ }^{22}$ The first extension technique (left side of Figure 3), where missing persons are reallocated to the income group corresponding to their income when being alive; the second extension technique (right side of Figure 3), where all missing persons are reallocated to the welfareneutral income group $y_{N} \cdot{ }^{23}$
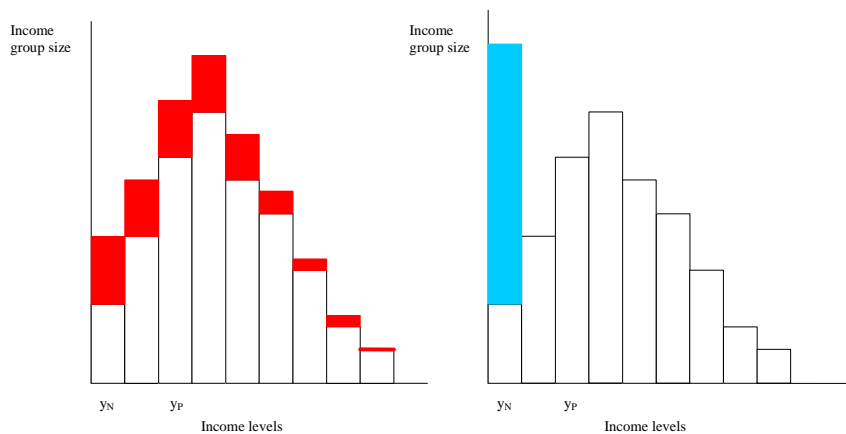

Figure 3: Two alternative adjustments of the income distribution

\subsection{Results}

Let us first consider the simple case where the fictitious income $e_{i}$ used for the extension is the one enjoyed when being alive, i.e. $y_{i}$. For that purpose, we will proceed in two stages. We will first compute the poverty rate for age 60 and more for each gender and region, for the new population computed above, while assuming that the poverty threshold takes the same level as before the adjustment. Then, we will compute adjusted poverty rates under a new poverty line (taking the modification of the income distribution into account).

Table 2 shows that, if one keeps the poverty threshold of Table 1, adjusted poverty rates are larger than standard poverty rates. That result is not surprising: our correction, by adding the "missing" persons, consists in adding relatively more poor individuals than non-poor individuals. Hence, under a fixed poverty threshold, there must be a rise in the poverty rate. That adjustment is relatively constant across genders and regions, and equal to about 1 point. Such an adjustment, which can be interpreted as the downward bias due to the Mortality Paradox, may be regarded as either low or high. On the one hand, when one considers poverty rates of about $20 \%$, the addition of one point is a minor adjustment. On the other hand, that adjustment looks significant once we think that 1 percent of the population under study consists of thousands of persons and families.

\footnotetext{
${ }^{22}$ Throughout this section, the poverty rate is the percentage of the population below the poverty line $y_{P}$, fixed to $60 \%$ of the median income.

${ }^{23}$ On Figure 3, the income distribution is purely hypothetical, and only serves to illustrate the two alternative ways to incorporate prematurely dead persons in the income distribution.
} 
Whereas the first part of Table 2 is based on the pre-adjustment poverty threshold, the modification of the population groups in such a way as to neutralize the impact of differential mortality has also the effect of changing the income distribution as a whole. Hence, if one adheres to a relativist - rather than absolutist - view of poverty, the addition of "missing" individuals may also affect the level of the poverty threshold. If one computes that new threshold, we obtain a poverty line that is 125 euros lower than the initial one. Under that new threshold, poverty rates tend to fall to levels that are close (if not inferior) to unadjusted poverty rates (second part of Table 2). Thus, if one adheres to a relativist view of poverty, taking the "missing" individuals into account may reduce - rather than raise - poverty.

\begin{tabular}{|c|c|c|c|}
\hline & Belgium & Flanders & Wallonia \\
\hline \multicolumn{4}{|c|}{ Pre-adjustment poverty threshold (10236 euros) } \\
\hline Total population & $21.7 \%$ & $21.1 \%$ & $21.3 \%$ \\
\hline Men & $19.8 \%$ & $19.3 \%$ & $20.1 \%$ \\
\hline Women & $23.3 \%$ & $22.7 \%$ & $22.3 \%$ \\
\hline \multicolumn{4}{|c|}{ New poverty threshold (10109 euros) } \\
\hline Total population & $20.5 \%$ & $20.2 \%$ & $20.0 \%$ \\
\hline Men & $18.7 \%$ & $18.3 \%$ & $18.4 \%$ \\
\hline Women & $22.1 \%$ & $21.8 \%$ & $21.2 \%$ \\
\hline
\end{tabular}

Therefore, whether counting the "missing" persons affects the measured poverty or not depends on whether we adhere to an absolutist or a relativistic view of poverty. In the former case, adding the prematurely dead raises poverty. In the latter case, the fall in the poverty threshold is such that the poverty rate is close - if not lower - than before the adjustment. Those results raise the question of the "right" poverty threshold. We will not address that general issue here, and we will propose poverty measures under the two kinds of threshold.

Whereas Table 2 presupposed that the fictitious income equals the income when being alive, one can consider other values for that fictitious income. As discussed above, a natural candidate is the welfare-neutral income. To estimate that welfare-neutral income, we use here the recent literature on the measurement of welfare losses induced by premature death allows us to derive more precise estimates of the welfare-neutral income. For that purpose, let us assume, like Becker et al. (2005), that agents have the temporal utility function:

$$
u\left(y_{i}\right)=\frac{\left(y_{i}\right)^{1-1 / \gamma}}{1-1 / \gamma}+\alpha
$$

Following Becker et al. (2005), we fix $\gamma=1.25$. We estimate the intercept $\alpha$ on the basis of the average income in our database, and we obtain: $\alpha=-15.50$. On the basis of those estimates, we obtain a welfare-neutral income equal to 284 euros. Table 3 shows adjusted poverty rates under that fictitious income.

Adjusted poverty rates under the welfare-neutral fictitious income are larger than under fictitious incomes equal to the income when being alive, and, also, larger than unadjusted poverty measures. It is also important to decompose the adjustment into (1) counting the "missing poor"; (2) counting premature death 
as a part of poverty. The first adjustment explains the gap between poverty rates in Tables 1 and 2 . That change is small - about 1 point - and not robust to the chosen poverty threshold. The second adjustment explains the poverty differentials between Tables 2 and 3. That differential is large - about 6-7 points - and quite robust to the chosen poverty threshold.

Another important observation to be made concerns the gender poverty gap. In unadjusted terms, Walloon women are poorer than Walloon men $(21.6 \%$ against $18.9 \%$ ). In adjusted terms, and taking past incomes as a basis for the fictitious income, women are still more poor than men $(22.3 \%$ against 20.1 $\%$ ). However, once we count premature death as a part of poverty, we obtain the opposite ranking: Walloon men, because of their worse survival conditions, turn out to be poorer than Walloon women (31.9\% against $29.4 \%$ ). Hence, the choice of fictitious incomes is relevant not only for the description of aggregate outcomes, but, also, for the description of poverty differentials between groups.

Table 3: Adjusted poverty rates 60+: welfare-neutral fictitious income

\begin{tabular}{|c|c|c|c|}
\hline & Belgium & Flanders & Wallonia \\
\hline \multicolumn{4}{|c|}{ Pre-adjustment poverty threshold (10236 euros) } \\
\hline Total population & $29.0 \%$ & $27.5 \%$ & $30.6 \%$ \\
\hline Men & $28.8 \%$ & $26.9 \%$ & $31.9 \%$ \\
\hline Women & $29.1 \%$ & $27.9 \%$ & $29.4 \%$ \\
\hline \multicolumn{4}{|c|}{ New poverty threshold (10031 euros) } \\
\hline Total population & $27.3 \%$ & $25.9 \%$ & $28.5 \%$ \\
\hline Men & $27.2 \%$ & $25.5 \%$ & $29.6 \%$ \\
\hline Women & $27.3 \%$ & $26.3 \%$ & $27.6 \%$ \\
\hline
\end{tabular}

\subsection{Further results: FGT poverty measures}

Our empirical illustration has so far focused only on standard head-count ratios. However, as stressed by Kanbur and Mukherjee (2007), the Mortality Paradox leads to a measurement bias for a broad class of poverty measures, and not only for head-count ratios. In order to investigate to what extent other poverty measures, also suffer from the noise induced by income-differentiated mortality, we propose here to carry out the same exercise as above, but while using, for each region, the Foster Greer Thorbecke (1984) poverty measure:

$$
P_{\alpha}=\frac{1}{N} \sum_{i=1}^{P-1}\left(\frac{y_{P}-y_{i}}{y_{P}}\right)^{\alpha}
$$

As it is well-known, the FGT measure with $\alpha=0$, i.e. $P_{0}$, is the standard headcount poverty ratio; when $\alpha=1$, the FGT measure, denoted by $P_{1}$, consists of the average of poverty gaps ratios, and, as such, captures also the depth of the poverty phenomenon. When $\alpha=2$, the FGT measure, denoted by $P_{2}$, is the average of squared poverty gap ratios.

We will compare here standard, unadjusted FGT measures, with the ones computed on the basis of the adjusted income distribution, as above. Table 4 below shows the unadjusted FGT poverty measures for the Belgian population aged 60 and more. Table 4 shows that, although old-age poverty is, except for females, larger in Wallonia than in Flanders on the basis of head-count ratios, the same is no longer true once we consider poverty gap ratios or squared poverty 
gap ratios. That somewhat surprising result is probably due to the larger life expectancy in Flanders (see above), which leads to a larger depth of poverty for the elderly, in comparison to Wallonia.

Table 4: FGT poverty measures at age $60+$ in Belgium

\begin{tabular}{cccc}
\hline \hline \multicolumn{5}{c}{ Belgium } & Flanders & Wallonia \\
\hline Head-count ratio $\left(P_{0}\right)$ \\
\hline Total population & $20.8 \%$ & $20.2 \%$ & $20.4 \%$ \\
Male & $18.7 \%$ & $18.3 \%$ & $18.9 \%$ \\
Female & $22.4 \%$ & $21.9 \%$ & $21.6 \%$ \\
\hline \multicolumn{5}{c}{ Poverty gap ratio $\left(P_{1}\right)$} \\
\hline Total population & $4.2 \%$ & $4.0 \%$ & $3.8 \%$ \\
Male & $3.6 \%$ & $3.5 \%$ & $3.4 \%$ \\
Female & $4.7 \%$ & $4.4 \%$ & $4.1 \%$ \\
\hline \multicolumn{5}{c}{ Squared poverty gap ratio $\left(P_{2}\right)$} \\
\hline Total population & $1.5 \%$ & $1.4 \%$ & $1.1 \%$ \\
Male & $1.2 \%$ & $1.1 \%$ & $1.0 \%$ \\
Female & $1.8 \%$ & $1.6 \%$ & $1.2 \%$ \\
\hline \hline
\end{tabular}

As shown by Table 5, which gives adjusted FGT measures under a fictitious income equal to the past income when being alive, the size of the adjustment is significant when the poverty line remains unchanged: the overall $P_{1}$ index for Belgians aged $60+$ grows from $4.2 \%$ to $4.4 \%$, whereas the $P_{2}$ index grows from $1.5 \%$ to $1.6 \%$. Thus the inclusion of "missing" persons affects not only the counting of the poor, but, also the measured depth of poverty. Note that, as with head-count ratios, the adjustment is less sizeable once the poverty line is also adjusted to the new, extended population.

Finally, assigning a fictitious income equal to the welfare-neutral income leads to much larger adjustments, as shown on Table 6 . For the entire population aged $60+$, the average of poverty gaps $P_{1}$ increases from $4.2 \%$ without adjustment to $13.9 \%$ for the adjusted measure. The average of squared poverty gaps $P_{2}$ is raised from $1.5 \%$ to $11.2 \%$. Those adjustments are much larger than those under a fictitious income equal to past income. Moreover, those adjustments are, in relative terms, more sizeable than when considering head-count ratios (i.e. $P_{0}$ ). This suggests that taking the prematurely dead into account has an even larger impact on poverty measurement once the depth of poverty is also measured. Thus the Mortality Paradox raises measurement difficulties for a broad class of poverty measures, going far beyond standard head-count ratios. 
Table 5: Adjusted FGT measures at age 60+: fictitious income $=$ past income

\begin{tabular}{|c|c|c|c|c|}
\hline & & Belgium & Flanders & Wallonia \\
\hline \multicolumn{5}{|c|}{ Pre-adjustment poverty threshold (10236 euros) } \\
\hline \multirow[t]{3}{*}{ Total population } & $P_{0}$ & $21.7 \%$ & $21.1 \%$ & $21.3 \%$ \\
\hline & $P_{1}$ & $4.4 \%$ & $4.2 \%$ & $4.0 \%$ \\
\hline & $P_{2}$ & $1.6 \%$ & $1.5 \%$ & $1.2 \%$ \\
\hline \multirow[t]{3}{*}{ Male } & $P_{0}$ & $19.8 \%$ & $19.3 \%$ & $20.1 \%$ \\
\hline & $P_{1}$ & $3.8 \%$ & $3.7 \%$ & $3.6 \%$ \\
\hline & $P_{2}$ & $1.3 \%$ & $1.2 \%$ & $1.1 \%$ \\
\hline \multirow[t]{3}{*}{ Female } & $P_{0}$ & $23.3 \%$ & $22.7 \%$ & $22.3 \%$ \\
\hline & $P_{1}$ & $4.9 \%$ & $4.5 \%$ & $4.3 \%$ \\
\hline & $P_{2}$ & $1.8 \%$ & $1.7 \%$ & $1.3 \%$ \\
\hline \multicolumn{5}{|c|}{ New poverty threshold (10109 euros) } \\
\hline \multirow[t]{3}{*}{ Total population } & $P_{0}$ & $20.5 \%$ & $20.2 \%$ & $20.0 \%$ \\
\hline & $P_{1}$ & $4.2 \%$ & $3.9 \%$ & $3.8 \%$ \\
\hline & $P_{2}$ & $1.5 \%$ & $1.4 \%$ & $1.1 \%$ \\
\hline \multirow[t]{3}{*}{ Male } & $P_{0}$ & $18.7 \%$ & $18.3 \%$ & $18.4 \%$ \\
\hline & $P_{1}$ & $3.7 \%$ & $3.5 \%$ & $3.5 \%$ \\
\hline & $P_{2}$ & $1.2 \%$ & $1.1 \%$ & $1.0 \%$ \\
\hline \multirow[t]{3}{*}{ Female } & $P_{0}$ & $22.1 \%$ & $21.8 \%$ & $21.2 \%$ \\
\hline & $P_{1}$ & $4.6 \%$ & $4.3 \%$ & $4.0 \%$ \\
\hline & $P_{2}$ & $1.8 \%$ & $1.6 \%$ & $1.2 \%$ \\
\hline
\end{tabular}

Table 6: Adjusted FGT measures at age 60+: fictitious income $=$ welfare-neutral income

\begin{tabular}{ccccc}
\hline \hline \multicolumn{5}{c}{ Pre-adjustment poverty threshold $(10236$ euros $)$} \\
\hline Total population & $P_{0}$ & $29.0 \%$ & $27.5 \%$ & $30.6 \%$ \\
& $P_{1}$ & $13.9 \%$ & $12.5 \%$ & $15.7 \%$ \\
& $P_{2}$ & $11.2 \%$ & $9.9 \%$ & $13.0 \%$ \\
Male & $P_{0}$ & $28.8 \%$ & $26.9 \%$ & $31.9 \%$ \\
& $P_{1}$ & $15.3 \%$ & $13.4 \%$ & $18.5 \%$ \\
Female & $P_{2}$ & $12.8 \%$ & $11.0 \%$ & $16.0 \%$ \\
& $P_{0}$ & $29.1 \%$ & $27.9 \%$ & $29.4 \%$ \\
& $P_{1}$ & $12.7 \%$ & $11.7 \%$ & $13.5 \%$ \\
& $P_{2}$ & $9.8 \%$ & $8.9 \%$ & $10.6 \%$ \\
\hline Total population & $P_{0}$ & $27.3 \%$ & $25.9 \%$ & $28.5 \%$ \\
& $P_{1}$ & $13.6 \%$ & $12.2 \%$ & $15.4 \%$ \\
& $P_{2}$ & $11.1 \%$ & $9.8 \%$ & $12.9 \%$ \\
& $P_{0}$ & $27.2 \%$ & $25.5 \%$ & $29.6 \%$ \\
Female & $P_{1}$ & $15.0 \%$ & $13.1 \%$ & $18.2 \%$ \\
& $P_{2}$ & $12.7 \%$ & $10.9 \%$ & $15.9 \%$ \\
& $P_{0}$ & $27.3 \%$ & $26.3 \%$ & $27.6 \%$ \\
& $P_{1}$ & $12.4 \%$ & $11.3 \%$ & $13.2 \%$ \\
& $P_{2}$ & $9.7 \%$ & $8.8 \%$ & $10.5 \%$ \\
\hline \hline
\end{tabular}




\section{Conclusions}

Under income-differentiated mortality, poverty measures reflect not only the "true" poverty, but, also, the interferences due to the survival process. That dependency on survival laws leads to the Mortality Paradox: the worse the survival conditions of the poor are, the lower the measured poverty is.

We proposed to re-examine a solution to that paradox, which consists of extending lifetime income profiles, to take the "missing poor" into account. For that purpose, we developed a two-period model with income mobility and income-differentiated mortality. We identified two conditions under which the extension of income profiles allows head-count poverty ratios to satisfy a weak requirement of independence from survival conditions (No Mobility Same Poverty): (1) the fictitious income is assigned only to the prematurely dead poor; (2) that fictitious income does not exceed the income when being alive.

Although those conditions are intuitive, these suffer from two major drawbacks. First, condition (1) is not compatible with the idea that a premature death is a source of poverty for all individuals who face it. Second, condition (2) does not help us a lot regarding the choice of a particular fictitious income, which is problematic for empirical applications. Therefore, we proposed to extend the adjustment to all prematurely dead persons, and to use, as a fictitious income, the welfare-neutral income, i.e. the income making an individual indifferent between life continuation and death.

Finally, we used regional Belgian data to estimate the size of the Mortality Paradox, as well as the robustness of adjusted poverty measures to the fictitious incomes used. We showed that the extension of income profiles by means of fictitious incomes equal to the incomes when being alive leads to a rise of about 1 point of poverty rate at age 60 and more. But once the poverty threshold is modified to fit the adjusted income distribution, the adjusted poverty rate becomes close to the unadjusted one. We also compute adjusted poverty rates under welfare-neutral fictitious incomes, and showed that such an alternative adjustment raises poverty rates by about 6 to 7 points. Hence, while the mere addition of the "missing" individuals under a constant income leads to a minor variation in the magnitude of poverty, the monetization of premature death by means of the welfare-neutral fictitious income raises the magnitude of poverty. Similar comparisons made on the basis of FGT poverty measures confirmed those findings, and showed even larger adjustments, since the assignment of a welfare-neutral fictitious income to the prematurely dead substantially raises the depth of the poverty phenomenon, as measured by (squared) poverty gaps.

Those findings have strong corollaries for policy-making. Suppose that a government can choose between two policies: on the one hand, a transfer program towards the elderly poor; on the other hand, a free access to health care services below some income level. Undoubtedly, the first policy would reduce the standard old-age poverty rate, but the second policy, by increasing the number of poor persons surviving to the old age, would raise the old-age poverty measure. Relying on standard poverty measures would thus favor the first policy. On the contrary, if one uses adjusted old-age poverty measures, the first policy, by focusing on the surviving old, would only reduce poverty to a small extent, whereas the second policy, by preventing lots of premature deaths, would strongly reduce the (so-measured) poverty. Thus the way in which poverty is measured is far from neutral regarding the assessment of social policies. 
Note that the influence of public policies on the number and identities of living individuals has been largely discussed in the population ethics literature. ${ }^{24}$ The specificity of the problem at stake here lies in the fact that such an influence is affected by something that appears, at first glance, to be "neutral": the poverty indicator that is used. The present paper shows that the precise way in which poverty measures treat the prematurely dead persons is far from neutral for policy valuation, and, at the end of the day, for policy-making.

In sum, the comparison of standard poverty rates with adjusted ones reveals that the impact of income-differentiated mortality on the measurement of poverty is far from benign. One should thus be careful when interpreting the levels and variations of usual old-age poverty measures. Those measures hide not only a large number of "missing" poor, but, also, a strong form of deprivation: premature death. Thus, two centuries after Malthus' treatise, a particular attention should still be paid to the positive population checks at work in our economies. Otherwise, if we do as if positive checks do not exist, social statistics - including the ones on poverty - will be hardly useful for policy-makers.

\section{References}

Becker, G.S., Philipson, T. \& Soares, R. (2005): "The quantity and the quality of life and the evolution of world inequality", American Economic Review, 95 (1), pp. 277-291.

Bossuyt N, Gadeyne S, Deboosere P, Van Oyen H (2004): "Socio-economic inequalities in healthy expectancy in Belgium", Public Health 118, pp. 3-10.

Broome, J. (1992): Counting the Cost of Global Warming, The White Horse Press: Cambridge.

Broome, J. (2004): Weighing Lives. Oxford University Press: New-York.

Deaton, A. \& Paxson, C. (1998): "Aging and inequality in income and health", American Economic Review, 88, pp. 248-253.

Deaton, A. (2003): "Health, inequality and economic development", Journal of Economic Literature, 41, pp. 113-158.

Deboosere, P, Gadeyne, S. \& Van Oyen H (2009): "The 1991-2004 Evolution in Life Expectancy by Educational Level in Belgium Based on Linked Census and Population Register Data", European Journal of Population, 25, pp. 175-196.

Duleep, H.O. (1986): "Measuring the effect of income on adult mortality using longitudinal administrative record data", Journal of Human Resources, 21 (2), pp. 238-251.

Fleurbaey, M., Leroux, M-L. \& Ponthiere, G. (2011): "Compensating the dead", Princeton Economic Theory Center Working Paper 028-2011.

Foster, J., Greer, J. \& Thorbecke, E. (1984): "A class of decomposable poverty measures", Econometrica, 52 (3), pp. 761-766.

Jusot, F. (2003): "Inégalités sociales de mortalité: effet de la pauvreté ou de la richesse", mimeo.

Kanbur, R. \& Mukherjee, D. (2007): "Premature mortality and poverty measurement", Bulletin of Economic Research, 59 (4), pp. 339-359.

Malthus, T. (1798): An Essay on the Principle of Population, London.

Mukherjee, D. (2001): "Measuring multidimensional deprivation", Mathematical Social Sciences, 42, pp. 233-251.

Pamuk, E.R. (1985): "Social class inequality in mortality from 1921 to 1972 in England and Wales", Population Studies, 39, 17-31.

\footnotetext{
${ }^{24}$ See Parfit (1984) and Broome (1992, 2004).
} 
Pamuk, E.R. (1988): "Social class inequality in infant mortality in England and Wales from 1921 to 1980", European Journal of Population, 4, pp. 1-21.

Parfit, D. (1984): Reasons and Persons, Oxford University Press: New-York.

Salm, M. (2007): "The effect of pensions on longevity: evidence from Union Army veterans", IZA Discussion Paper 2668.

Sen, A. K. (1976): "Poverty: an ordinal approach to measurement", Econometrica, 44, pp. 219-231.

Sen, A.K. (1998): "Mortality as an indicator of economic success and failure", Economic Journal, 108, pp. 1-25.

Snyder, S. \& W. Evans (2006): "The effect of income on mortality: evidence from the social security notch", Review of Economics and Statistics, 88 (3), pp. 482-495.

UNDP (1997): The Human Development Report, Oxford University Press: New-York.

Usher, D. (1980): The Measurement of Economic Growth, Basil Blackwell: Oxford.

Van Oyen, H., Bossuyt, N., Deboosere, P., Gadeyne, S., Abatith, E. \& Demarest, S. (2005): "Differential inequity in health expectancy by region in Belgium", Social Preventive Medicine, 50 (5), pp. 301-310.

Viscusi, W.K. (1998): Rational Risk Policy, Clarendon Press: Oxford.

\section{Appendix}

\subsection{Proof of Lemma 1}

We want to show that RMC implies NMSP. Let us start from a situation where all individuals reach the old age. Assuming the absence of mobility, we get: $P^{2}=$ $P^{1}$. Consider now a deterioration of survival conditions for some income group. As poverty rates at the young age do not depend on survival, we get: $P^{1}=P^{1 \prime}$ (as everything else except the deterioration is left unchanged). Moreover, we have, by RMC, that $P^{2 \prime}=P^{2}$. Hence, by transitivity, we have $P^{2 \prime}=P^{2}=P^{1}=$ $P^{1 \prime}$. Hence, it follows that, in the absence of income mobility, we have $P^{1 \prime}=P^{2 \prime}$, in conformity with NMSP. Given that any survival conditions can be obtained by departing from the conditions where everyone survives, we necessarily have, under RMC, that the poverty rate is constant across the lifecycle in the absence of mobility, that is, that NMSP holds.

Note that the reverse implication does not hold. NMSP does not necessarily imply RMC. Actually, NMSP implies RMC only in the case where there is no income mobility. To see this, take a situation with poverty rate at the young age equal to $P^{1}$. By the NMSP condition, we know that, in the absence of mobility, we have $P^{1}=P^{2}$. Take now another situation, with the same poverty rate at the young age, equal to $P^{1 \prime}=P^{1}$, but with a worsening of the survival probability for some income level. By the NMSP condition, we know that, in the absence of mobility, we have $P^{1 \prime}=P^{2 \prime}$. But as $P^{1 \prime}=P^{1}$, it follows, by transitivity of equality, that $P^{2}=P^{2 \prime}$, in conformity with RMC. Thus we have that NMSP implies RMC in the absence of income mobility. But nothing can be said on the general case with income mobility.

\subsection{Proof of Proposition 1}

By Lemma 1, we can prove that proposition by merely showing that the old-age poverty rate violates NMSP. NMSP requires that, if no mobility, i.e. $\lambda_{i i}=1$ for 
all $i$, poverty at the young age and at the old age should be the same. In the absence of mobility, $P^{2}$ is:

$$
P^{2}=\frac{\sum_{i=1}^{K} \pi_{i} n_{i}^{1}\left(\sum_{j=1}^{P-1} \lambda_{i j}\right)}{\sum_{k=1}^{K} \pi_{k} n_{k}^{1}}=\frac{\sum_{i=1}^{P-1} \pi_{i} n_{i}^{1}}{\sum_{k=1}^{K} \pi_{k} n_{k}^{1}}
$$

Given $\pi_{1}<\ldots<\pi_{K}$, this cannot be equal to $P^{1}=\frac{\sum_{i=1}^{P-1} n_{i}^{1}}{\sum_{k=1}^{K} n_{k}^{1}}$.

Actually, in $P^{2}$, low income group numbers receive lower weights than under $P^{1}$ (where the weights are unitary). Hence, it is easy to see that: $P^{2}<P^{1}$, which goes against NMSP. By Lemma 1, we also know that $P^{2}$ does not satisfy RMC.

\subsection{Proof of Proposition 2}

Consider first the case where only the initially poor who died prematurely are assigned a fictitious income. In that case, we have:

- If $e_{i}<y_{P}$ for all $i$, we have, in the absence of income mobility among those who are alive:

$$
\hat{P}^{2}=\frac{\sum_{i=1}^{P-1} \pi_{i} n_{i}^{1}+\sum_{i=1}^{P-1}\left(1-\pi_{i}\right) n_{i}^{1}}{\sum_{k=1}^{K} n_{k}^{1}}=P^{1}=\frac{\sum_{i=1}^{P-1} n_{i}^{1}}{\sum_{k=1}^{K} n_{k}^{1}}
$$

Thus NMSP is satisfied.

- If $e_{i}<y_{P}$ for all $i<R \leq P$ and $e_{i} \geq y_{P}$ for all $i \geq R$, we have, in the absence of income mobility:

$$
\hat{P}^{2}=\frac{\sum_{i=1}^{P-1} \pi_{i} n_{i}^{1}+\sum_{i=1}^{R-1}\left(1-\pi_{i}\right) n_{i}^{1}}{\sum_{k=1}^{K} n_{k}^{1}}<P^{1}=\frac{\sum_{i=1}^{P-1} n_{i}^{1}}{\sum_{k=1}^{K} n_{k}^{1}}
$$

Hence NMSP is not satisfied here.

- If $e_{i} \geq y_{P}$ for all $i$, we have, in the absence of income mobility:

$$
\hat{P}^{2}=\frac{\sum_{i=1}^{K} \pi_{i} n_{i}^{1}}{\sum_{k=1}^{K} n_{k}^{1}}<P^{1}=\frac{\sum_{i=1}^{P-1} n_{i}^{1}}{\sum_{k=1}^{K} n_{k}^{1}}
$$

Thus the adjusted poverty measure does not satisfy NMSP.

Let us now consider the case where a fictitious income level is assigned to all premature dead persons. We have the following three cases:

- If $e_{i}<y_{P}$ for all $i$, we have, in the absence of income mobility:

$$
\hat{P}^{2}=\frac{\sum_{i=1}^{P-1} \pi_{i} n_{i}^{1}+\sum_{i=1}^{K}\left(1-\pi_{i}\right) n_{i}^{1}}{\sum_{k=1}^{K} n_{k}^{1}}>P^{1}=\frac{\sum_{i=1}^{P-1} n_{i}^{1}}{\sum_{k=1}^{K} n_{k}^{1}}
$$

Thus $\hat{P}^{2}>P^{1}$, because the premature deaths who used to be rich are now counted as poor. However, when $\pi_{i} \rightarrow 1$ for $e_{i}>y_{P}$, we have:

$$
\hat{P}^{2}=\frac{\sum_{i=1}^{P-1} n_{i}^{1}+}{\sum_{k=1}^{K} n_{k}^{1}}+\underbrace{\frac{\sum_{i=P}^{K}\left(1-\pi_{i}\right) n_{i}^{1}}{\sum_{k=1}^{K} n_{k}^{1}}}_{\approx 0} \approx P^{1}=\frac{\sum_{i=1}^{P-1} n_{i}^{1}}{\sum_{k=1}^{K} n_{k}^{1}}
$$


Hence under a low mortality of the non-poor, the adjusted poverty rate is close to satisfy NMSP.

- If $e_{i}<y_{P}$ for all $i<R \leq P$ and $e_{i} \geq y_{P}$ for all $i \geq R$, we have, in the absence of income mobility:

$$
\hat{P}^{2}=\frac{\sum_{i=1}^{P-1} \pi_{i} n_{i}^{1}+\sum_{i=1}^{R-1}\left(1-\pi_{i}\right) n_{i}^{1}}{\sum_{k=1}^{K} n_{k}^{1}} \lessgtr P^{1}=\frac{\sum_{i=1}^{P-1} n_{i}^{1}}{\sum_{k=1}^{K} n_{k}^{1}}
$$

- If $e_{i} \geq y_{P}$ for all $i$, we have, in the absence of income mobility:

$$
\hat{P}^{2}=\frac{\sum_{i=1}^{P-1} \pi_{i} n_{i}^{1}}{\sum_{k=1}^{K} n_{k}^{1}}<P^{1}=\frac{\sum_{i=1}^{P-1} n_{i}^{1}}{\sum_{k=1}^{K} n_{k}^{1}}
$$

Thus NMSP is not satisfied.

\subsection{Proof of Corollary 1}

Indeed, in that case, we have:

$$
\hat{P}^{2}=\frac{\sum_{i=1}^{K} \pi_{i} n_{i}^{1}\left(\sum_{j=1}^{P-1} \lambda_{i j}\right)+\sum_{i=1}^{P-1}\left(1-\pi_{i}\right) n_{i}^{1}}{\sum_{k=1}^{K} n_{k}^{1}}
$$

Hence, in the absence of income mobility, we have:

$$
\hat{P}^{2}=\frac{\sum_{i=1}^{P-1} \pi_{i} n_{i}^{1}+\sum_{i=1}^{P-1}\left(1-\pi_{i}\right) n_{i}^{1}}{\sum_{k=1}^{K} n_{k}^{1}}=\frac{\sum_{i=1}^{P-1} n_{i}^{1}}{\sum_{k=1}^{K} n_{k}^{1}}=P^{1}
$$

in conformity with NMSP.

\subsection{Proof of Proposition 3}

Under $y_{N}<y_{P}$, we have:

$$
\hat{P}^{2}=\frac{\sum_{i=1}^{K} \pi_{i} n_{i}^{1}\left(\sum_{j=1}^{P-1} \lambda_{i j}\right)+\sum_{i=1}^{K}\left(1-\pi_{i}\right) n_{i}^{1}}{\sum_{k=1}^{K} n_{k}^{1}}
$$

In the absence of mobility, this can be rewritten as:

$\hat{P}^{2}=\frac{\sum_{i=1}^{P-1} \pi_{i} n_{i}^{1}+\sum_{i=1}^{K}\left(1-\pi_{i}\right) n_{i}^{1}}{\sum_{k=1}^{K} n_{k}^{1}}=\frac{\sum_{i=1}^{P-1} n_{i}^{1}+\sum_{i=P}^{K}\left(1-\pi_{i}\right) n_{i}^{1}}{\sum_{k=1}^{K} n_{k}^{1}}>P^{1}=\frac{\sum_{i=1}^{P-1} n_{i}^{1}}{\sum_{k=1}^{K} n_{k}^{1}}$

Thus $\hat{P}^{2}>P^{1}$, because the premature deaths who used to be rich are now counted as poor.

Under $y_{N} \geq y_{P}$, we have:

$$
\hat{P}^{2}=\frac{\sum_{i=1}^{K} \pi_{i} n_{i}^{1}\left(\sum_{j=1}^{P-1} \lambda_{i j}\right)}{\sum_{k=1}^{K} n_{k}^{1}}
$$

Without income mobility, this becomes: $\hat{P}^{2}=\frac{\sum_{i=1}^{P-1} \pi_{i} n_{i}^{1}}{\sum_{k=1}^{K} n_{k}^{1}}<P^{1}=\frac{\sum_{i=1}^{P-1} n_{i}^{1}}{\sum_{k=1}^{K} n_{k}^{1}}$ 


\subsection{Data}

Poverty measures Poverty rates are obtained on the basis of the income data from the european survey EU-SILC. Individuals are taken as the unit of analysis. The income level assigned to each individual is computed by dividing the household income level by an equivalence scale. The equivalence scale that is used is the one of the OECD. That scale assigns a weight of 1 for the first adult in the household, a weight of 0.5 for other adults of (14 years or more) in the household, and a weight of 0.3 for household members less than 14 years-old.

The poverty rate gives the percentage of the population that does not enjoy an available equivalent income at least equal to $60 \%$ of the median available equivalent income (median income computed for the country as a whole).

Life tables by income class There are no lifetable by income in Belgium. However, there exist lifetables by education levels (Deboosere et al, 2009). From these tables, it is possible to estimate lifetables by income class using a weighted ordinary least square regression, as in Bossuyt et al (2004) and Van Oyen et al (2005) studies on health expectancy. Indeed, the position in the social hierarchy is mainly determined by the dimensions: occupation, income and education. Given that the income and education are highly related to one another, we can extrapolate mortality by income class on the basis of the mortality by education. The social position is determined by the educational attainment. A five-category classification is used: (1) no formal education; (2) primary education; (3) lower secondary education; (4) higher secondary education; (5) tertiary education. We assume that the position of a socio-economic group is determined by its relative position, defined as the mid-point of the proportion of group represents on an ordered scale of $100 \%$ (Pamuk, 1985, 1988).

The mortality rates of the educational groups in terms of their relative socioeconomic position is estimated using a weighted ordinary least square region of each region and sex and (5-year) age group using aggregate data. The weights are defined as the relative sizes of the educational levels in each age group. The slope of the regression line represents the difference in mortality between the bottom and the top of the socio-economic hierarchy. Once estimated, the coefficient is used to compute lifetable according to income by assuming that the social hierarchy is similar to education.

In our case, we used lifetables by age groups of five years in order to obtain sufficient subsample of each income class. Indeed, we consider one hundred different groups. Each income class is of $500 €$ except for the highest class which comprehend all income above $50000 €$. 